\title{
Five Decades of the Zener Equation
}

\author{
P. A. MANOHAR, M. FERRY and T. CHANDRA
}

Department of Materials Engineering, University of Wollongong, Northfields Avenue, Wollongong, NSW-2522, Australia. E-mail: pam07@uow.edu.au

(Received on March 11, 1998; accepted in final form on April 24, 1998)

The Zener equation was first reported by C. S. Smith in 1948 and since then it has become an integral part of any theory which deals with recovery, recrystallization and grain growth in particle-containing materials. Several modifications to the original equation have been made over the past five decades to improve its applicability to more realistic situations. This paper summarises these modifications and discusses which modifications are reasonable and justifiable based on the analytical models and experimental evidence reported in the literature. Several examples of the applications of the equation are provided to describe annealing phenomena in a wide variety of materials. The paper also examines the impact of the equation in the field of materials science and engineering and suggests a direction for its future development.

KEY WORDS: Zener equation; particle pinning; limiting grain size; recovery; recrystallization; grain growth.

\section{Background}

In 1948, Cyril Stanley Smith published a seminal paper $^{11}$ which outlined the fundamental principles of interpretation of microstructures in terms of the equilibrium between phase and grain interfaces. The paper included a paragraph from a private communication from Clarence Zener concerning grain growth in particle-containing materials which has become famous in the five decades since that date. Numerous attempts have been made since then to improve the so-called Zener equation. The present paper is a historical overview that traces the evolution of the equation and outlines its impact in the field of materials science and engineering.

Zener $^{1)}$ proposed that the driving pressure for grain growth due to the curvature of the grain boundary would be counteracted by a pinning (drag) pressure exerted by the particles on the boundary. As a consequence, normal grain growth would be completely inhibited when the grain size reached a critical maximum grain radius $\left(R_{\mathrm{c}}\right)$ given by:

$$
R_{\mathrm{c}}=4 r / 3 f
$$

where $R_{\mathrm{c}}$ is the Zener limit, $r$ the radius of the pinning particles and $f$ the volume fraction of particles. Equation (1) is known as the Zener Equation and its general form is given as:

$$
R_{\mathrm{c}}=K r / f^{m}
$$

where $K$ is a dimensionless constant and $m$ an index for $f$.

It should be pointed out at the outset that the Zener equation is not a theory of grain growth in particlecontaining materials. Any such theory must describe at least three parameters: (i) the mean grain size; (ii) the grain size distribution as a function of time, and (iii) the time-invariant grain growth rate. In this context, the Zener limit is simply the critical grain radius which neither grows nor shrinks due to the balance of driving and pinning pressures. The equation gives no information about the actual process of grain growth, the growth rate or the size distribution of grains. Nevertheless, Eq. (1) is of great significance because it demonstrated for the first time, both qualitatively and quantitatively that, for a given particle-containing material, an increase in the volume fraction of particle, and/or a decrease in particle size results in a decrease in grain size. It is an important factor in the achievement of a fine grain size in materials, such as microalloyed steels, aluminium alloys and many other industrially-significant particle-containing materials. Furthermore, it has played a pivotal role in the subsequent development of theories concerning annealing phenomena in particle-containing materials.

The derivation of Eq. (1) involved several assumptions which were addressed by the subsequent research to improve its applicability for describing grain growth in a variety of materials. The following sections will discuss the mathematical derivation of the equation, the assumptions made in its derivation, consequent modifications, the applications of the equation to studies of annealing phenomena and possible future developments.

\section{Derivation of the Zener Equation}

Zener did not provide a diagram for the interaction geometry of a particle with a grain boundary, but based on the description given by Smith $^{1)}$ a schematic illustration was prepared by Reed-Hil1 ${ }^{2}$ (Fig. 1). The derivation of the Zener equation can be divided into five steps: 


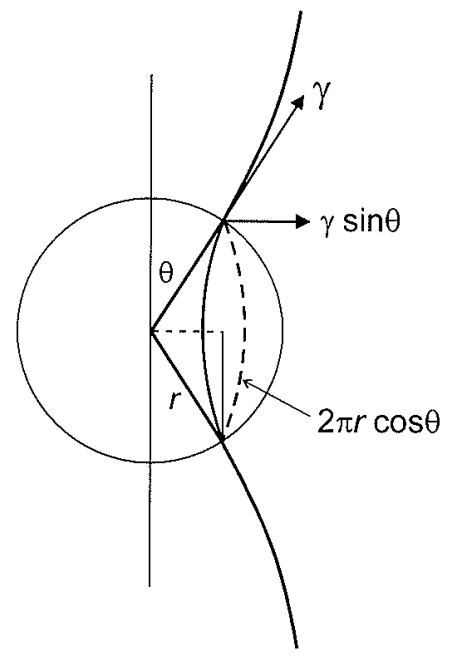

Fig. 1. Schematic diagram of the interaction of a spherical particle with a grain boundary (after Ref. 2)).

STEP 1: Calculation of maximum pinning (drag) force $\left(F_{z}\right)$ exerted by a single particle on the grain boundary (g.b.)

$F_{z}=($ total line of contact in three dimensions $) \times$ (component of surface tension in the direction opposite to the direction of movement of the g.b.)

This may be written as:

$$
F_{z}=2 \pi r \gamma \sin \theta \cos \theta
$$

For maximum pull, $\theta=45^{\circ}$ which gives the maximum pinning force per particle $\left(F_{z}\right)$ as:

$$
F_{\mathrm{z}}=\pi r \gamma
$$

$F_{z}$ is also called the Zener pinning force.

\section{STEP 2: Calculation of the surface density of particles} $\left(n_{\mathrm{s}}\right)$ on the grain boundary

$n_{\mathrm{s}}=\left\{\right.$ number of particles per unit volume $\left.\left(n_{\mathrm{v}}\right)\right\} \times(r)$

No explanation was given for this postulate. However, Gladman $^{3)}$ suggested that the condition which determines whether the particle is in contact with a grain boundary should be when the centre of the particle lies within $\pm r$ of the boundary. This idea was explained in more detail later by Nes et al. ${ }^{4)}$ where it was also suggested that $n_{\mathrm{v}}$ should be multiplied by $2 r$ since all particles within a distance $\pm r$ of the grain boundary (on both sides of the boundary) would interact with the boundary. This modification clearly increases the surface density of particles by a factor of two, but does not necessarily increase the pinning pressure by the same factor. The reason for this is that particles do not always interact with the grain boundary with maximum pinning force as assumed in Eq. (3b), so that the decreased $F_{z}$ would, to some extent, balance the increase in $n_{\mathrm{s}}$. The pinning force varies with contact angle according to the sine function (Eq. (3a)) and takes values from an attractive maximum at $\theta=-\pi / 4$ to a pinning maximum at $\theta=+\pi / 4$. Therefore, depending on the interaction position of the particles with respect to the grain boundary, the interaction force can either assist or resist the movement of the boundary. If all particles are randomly distributed (as assumed in the Zener analysis), there is a further problem in that the particles assisting and resisting the movement of the boundary may balance each other which would result into a net zero force on the boundary. However, it has been suggested ${ }^{3,4)}$ that this situation would only occur if the grain boundaries remain rigid, which is not the case. The boundaries are flexible and more highly curved near the particles. Therefore, the boundaries may remain in contact longer with the pinning particles than those assisting their movement, resulting in a net drag pressure. Thus, the resultant net drag pressure also depends on the assumptions made to characterise the grain boundaryparticle interaction geometry, and not only on $n_{\mathrm{s}}$. In view of this analysis, multiplying $n_{\mathrm{v}}$ by $2 r$ appears reasonable because it indicates more accurately how many particles interact with per unit area of a grain boundary.

Nevertheless, following the original proposal:

$n_{\mathrm{s}}=\{$ volume fraction of particles $(f) /$ volume of one spherical particle $\} \times r$

which may be written as:

$$
n_{\mathrm{s}}=3 f / 4 \pi r^{2}
$$

STEP 3: Calculation of the maximum pinning pressure due to all particles $\left(P_{\mathrm{z}}\right)$ on the grain boundary

$$
P_{\mathrm{z}}=F_{\mathrm{z}} n_{\mathrm{s}}=3 f \gamma / 4 r \quad \text { from Eqs. (3b) and (4)\} }
$$

If the suggestion of Gladman ${ }^{3)}$ and Nes et al. ${ }^{4)}$ is considered, then $P_{z}$ is given as:

$$
P_{\mathrm{z}}=3 f \gamma / 2 r
$$

Equation (5a) can also be written in the general form as:

$$
P_{z}=\gamma z
$$

where $z(=3 f / 4 r)$ is called the Zener factor. It is pertinent to note, however, that according to Gladman ${ }^{3)}$ and Nes et al. $^{4)}$ the Zener factor is given by:

$$
z=3 f / 2 r
$$

\section{STEP 4: Calculation of the driving pressure $\left(P_{g}\right)$ for} grain growth

Smith stated "... the driving force for grain growth is provided by the surface tension and is quantitatively equal to $\gamma / \rho_{\text {net }}$. To a first approximation, one can anticipate a definite relation between curvature of the boundary (virtually equal to grain size)...." From these statements, we construct an equation for $P_{\mathrm{g}}$, that is:

$$
P_{\mathrm{g}}=\gamma / \rho_{\text {net }}
$$

where $1 / \rho_{\text {net }}=1 / \rho_{1}+1 / \rho_{2}$, where $\rho_{1}$ and $\rho_{2}$ are the principal radii of curvature of the grain boundary. For a spherical grain, $\rho_{1}=\rho_{2}=\rho$ which leads to $\rho_{\text {net }}=\rho / 2$. Substituting this into Eq. (7a) yields:

$$
P_{\mathrm{g}}=2 \gamma / \rho
$$

The next problem is the relation between $\rho$ and the "grain size'. It is not clear whether Smith was referring to " $\rho_{\text {net }}$ " 
Table 1. Possible equations for the limiting grain radius $\left(R_{\mathrm{c}}\right)$.

\begin{tabular}{|c|c|c|c|c|c|}
\hline $\begin{array}{l}\text { Eq. }(7 \mathrm{c})= \\
\text { Eq. }(5 \mathrm{a})\end{array}$ & $\begin{array}{l}\text { Eq. }(7 c)= \\
\text { Eq. }(5 b)\end{array}$ & $\begin{array}{l}\text { Eq. }(7 d)= \\
\text { Eq. }(5 a)\end{array}$ & $\begin{array}{l}\text { Eq. }(7 d)= \\
\text { Eq. }(5 b)\end{array}$ & $\begin{array}{l}\text { Eq. }(7 e)= \\
\text { Eq. }(5 a)\end{array}$ & $\begin{array}{l}\text { Eq. }(7 e)= \\
\text { Eq. }(5 b)\end{array}$ \\
\hline$\gamma / R_{c}=3 f y / 4 r$ & $\gamma / R_{c}=3 f \gamma / 2 r$ & $\gamma / 2 R_{c}=3 f y / 4 r$ & $\gamma / 2 \mathrm{R}_{\mathrm{c}}=3 \mathrm{f} \gamma / 2 \mathrm{r}$ & $2 \gamma / R_{c}=3 f y / 4 r$ & $2 \gamma / R_{c}=3 f y / 2 r$ \\
\hline$R_{c}=4 r / 3 f$ & $R_{c}=2 r / 3 f$ & $R_{c}=2 r / 3 f$ & $R_{c}=r / 3 f$ & $R_{c}=8 r / 3 f$ & $R_{c}=4 r / 3 f$ \\
\hline Likely & Possible & Possible & Not possible & Not possible & Likely \\
\hline
\end{tabular}

or " $\rho$ " as the grain size. It is also unclear whether he was referring to " $R$ " (grain radius) or " $D$ " (grain diameter) as the grain size.

There are four possibilities:

(i) $\rho_{\text {net }}=R$, (ii) $\rho_{\text {net }}=D$, (iii) $\rho=R$, or (iv) $\rho=D$.

Substituting (i) and (ii) into Eq. (7a) gives:

$$
\begin{gathered}
P_{\mathrm{g}}=\gamma / R \\
P_{\mathrm{g}}=\gamma / D=\gamma / 2 R
\end{gathered}
$$

Substituting (iii) and (iv) into Eq. (7b) gives:

$$
\begin{array}{r}
P_{\mathrm{g}}=2 \gamma / R \quad \ldots \ldots \ldots \ldots \\
P_{\mathrm{g}}=2 \gamma / D=2 \gamma / 2 R=\gamma / R
\end{array}
$$

We thus have three different expressions for $P_{\mathrm{g}}$, namely $\gamma / 2 R, \gamma / R$ and $2 \gamma / R$.

STEP 5: Calculation of the equilibrium condition $\boldsymbol{P}_{\mathrm{z}}=\boldsymbol{P}_{\mathrm{g}}$

When the system is at equilibrium $\left(P_{\mathrm{z}}=P_{\mathrm{g}}\right)$, the grain radius is the Zener limit $\left(R_{\mathrm{c}}\right)$. As there are three possible equations for $P_{\mathrm{g}}$ \{Eqs. (7c), (7d) and $\left.(7 \mathrm{e})\right\}$ and two possible equations for $P_{\mathrm{z}}\{$ Eqs. (5a) and $(5 \mathrm{~b})\}$, there are six possible equations for $R_{\mathrm{c}}$ (Table 1). Therefore, the final result of Zener $\left(R_{\mathrm{c}}=4 r / 3 f\right)$ is achieved by the combination of either Eqs. (7c) and (5a) or Eqs. (7e) and $(5 b)$.

\section{Modifications of the Zener Equation}

Several assumptions were made either explicitly or implicitly in the derivation of Eq. (1), and this section summarises the modifications made by other workers over the past five decades. The most significant modifications are summarised chronologically in Table 2, which shows the evolution of the original equation. The following sections explain in some detail the key ideas which have resulted in the modifications listed in Table 2.

\subsection{Consideration of the Geometry of Particle-Grain Boundary Interaction}

In their consideration of the geometry of interaction between a particle and a grain boundary, Smith and Zener:

- assumed that grains and particles were spherical;

- considered the particles to be incoherent;

- considered the surface tension between grains $(\gamma)$ but ignored the interface tension between the grains and the particle, and

- did not consider the precise shape of the particlegrain boundary interface.
Gladman $^{3)}$ analysed the last of these points and concluded that a grain boundary cannot remain planar near a particle and that the grain boundary will be pulled towards the particle causing curvature, and arrived at:

$$
F_{z}=3.96 r \gamma
$$

This result is slightly higher than that due to Zener (Eq. (3b)).

The interaction of a coherent particle with a grain boundary was considered by Ashby et al. ${ }^{10)}$ who arrived at the following value for the Zener pinning force:

$$
F_{z}=2 \pi r \gamma
$$

This result is twice the value given by Zener (Eq. (3b)). Doherty $^{16)}$ accounted for the experimentally observed fact that small coherent particles can be dissolved (a process equivalent to the inverse of precipitation) by a moving grain boundary and derived an equation for $F_{\mathrm{z}}$ similar to that of Ashby et al. ${ }^{10}$ )

The effect of particle shape on $F_{z}$ was studied in detail by several workers. ${ }^{17,25)}$ Ryum et $a{ }^{17)}$ considered the effect of an ellipsoidal particle and its orientation with respect to the grain boundary on $F_{\mathrm{z}}$ and derived the following equations in terms of the eccentricity of the particle $(\varepsilon)$ and the maximum pinning force due to a spherical particle of the same volume $\left(F_{\mathrm{z}}^{\mathrm{s}}\right)$ :

For $\varepsilon \geq 1$, and when the major axis of the particle $(M)$ is perpendicular to the grain boundary

$$
F_{z}=F_{z}^{\mathrm{s}} / \pi\left[(1+2.14 \varepsilon) / \varepsilon^{0.33}\right]
$$

For $\varepsilon \leq 1$, and when $M$ is perpendicular to the grain boundary

$$
F_{z}=F_{z}^{s_{z}} \varepsilon^{0.47}
$$

When $M$ is parallel to the grain boundary

$$
F_{\mathrm{z}}=F_{\mathrm{z}}^{\mathrm{s}}\left[2 /(1+\varepsilon) \varepsilon^{0.33}\right]
$$

For highly eccentric particles such as thin plates and long needles meeting the boundary edge-on, the predicted pinning force is considerably greater than Eq. (3b). Ringer et al. $^{25)}$ showed that for cubic shaped particle of a given orientation, $F_{z}$ was approximately double the maximum pinning force offered by spherical particles of the same volume. By taking into account the surface tension between particles and grains, they found a significantly lower value of $\mathrm{K}$ in Eq. (2) (i.e. more effective pinning) compared with the value of 1.33 given by Zener.

The effect of grain shape (for truncated octahedra) on $P_{\mathrm{g}}$ was first considered by Haroun and Budworth ${ }^{8)}$ where it was suggested that $\rho=18 R$ which is significantly greater than $2 R$ as assumed in the Zener analysis. This 
ISIJ International, Vol. 38 (1998), No. 9

Table 2. Modifications of the Zener Equation (Arranged chronologically).

\begin{tabular}{|c|c|c|}
\hline Reference & Equation $\left(\mathbf{R}_{\mathrm{c}}=\right)$ & Comments \\
\hline Zener [Smith] (1948): Ref.[1] & $1.33 \mathrm{r} / \mathrm{f}$ & Original equation $\left(P_{B}=2 \gamma / \rho, \rho=D\right.$, so that $\left.P_{B}=\gamma / R\right)$ \\
\hline Fullman (1952): Ref. [5] & $1.33 / \mathrm{I}$ where $\mathrm{I}=\in \mathrm{f}(\mathrm{r}) / \mathrm{r}$ & $\begin{array}{l}\text { l is a dirt factor which accounts for a range of particles; } f(r) \text { is the volume fraction of spherical particles of radius } r\left(P_{g}=2 \gamma / \rho, \rho=D \text {, so }\right. \\
\left.\text { that } P_{g}=\gamma / R\right) \text {. }\end{array}$ \\
\hline Hillert (1965): Ref. [6] & $0.44 \mathrm{r} / \mathrm{f}$ & $\begin{array}{l}\text { Lower limit for normal grain growth inhibition. } \\
\text { Upper limit for total grain growth inhibition. } \\
\text { Considered the effect of grain size distribution on grain growth. } P_{B} \propto\left(1 / R_{c r}-1 / R \pm z\right) \text {. }\end{array}$ \\
\hline $\begin{array}{l}\text { Gladman (1966): Ref. [3] and } \\
\text { Gladman (1967): Ref. [7] }\end{array}$ & $\begin{array}{l}{[\pi(1 / 4-1 / 3 Z)] \mathrm{r} / \mathrm{f} \cong} \\
0.05-0.26 \mathrm{r} / \mathrm{f}\end{array}$ & $\begin{array}{l}\text { Driving force is considered to be a function of grain size distribution which is therefore proportional to } Z \text { and so } R_{c} \text { depends on the } \\
\text { value of } Z \text { (typically, } Z=1.41 \text { and } 2.0 \text { ). } Z \text { is the heterogeneity factor and } Z \geq 4 / 3 \text { for grain growth to occur. }\end{array}$ \\
\hline $\begin{array}{l}\text { Haroun and Budworth (1968): } \\
\text { Ref. [8] }\end{array}$ & $\begin{array}{l}0.074 \mathrm{r} / \mathrm{f} \\
1.03 \mathrm{r} / \mathrm{f}^{0.5}\end{array}$ & $\begin{array}{l}\text { Considered } \rho=18 \mathrm{R} \text {, and not } \rho=2 \mathrm{R} \text { as assumed by Zener. } \\
\text { Modified Zener equation under the condition that at least one particle exists on each grain boundary. } \\
\text { (Both equations were derived for a truncated octahedral grain shape and yield similar results for } f=0.5 \% \text { ). }\end{array}$ \\
\hline $\begin{array}{l}\text { Wold and Chambers (1968): } \\
\text { Ref. [9] }\end{array}$ & $2 r / 3 k f\left[\left(3 Z_{\max }-4\right) /\left(2 Z_{\max }\right)\right]$ & $\begin{array}{l}\text { Proposed } k>1 \text { after considering that particles would be present preferentially on the grain boundaries rather than in the grain interior. } \\
\text { They also combined Gladman approach. }\end{array}$ \\
\hline Ashby et al. (1969): Ref. [10] & $0.33 r / f^{*}$ & $\begin{array}{l}\text { Determined that } F_{z}=2 \pi r \gamma \text { which is twice the value given by Zener. They also considered the effect of coherency of particles on the } \\
\text { maximum pinning force }\left(n_{s}=3 f / 2 \pi r^{2} \text { and } P_{B}=\gamma / R\right) \text {. }\end{array}$ \\
\hline $\begin{array}{l}\text { Hellman and Hillert (1975): } \\
\text { Ref. [11] }\end{array}$ & $\begin{array}{l}4 \mathrm{r} / 9 \beta \mathrm{f} \cong 0.28 \cdot 0.59 \mathrm{r} / \mathrm{f} \\
\beta=0.125 \ln (40 \mathrm{p} / \mathrm{r})\end{array}$ & $\begin{array}{l}\text { Depending on the value of } \rho / r \text {, which can be between } 10^{1}-10^{4}, \beta \text { is expected to decrease as the volume fraction increases. The authors } \\
\text { also suggested } \rho=6 \mathrm{R} \text {. }\end{array}$ \\
\hline $\begin{array}{l}\text { Anand and Gurland (1975): } \\
\text { Ref. [12] }\end{array}$ & $1.18 \mathrm{r} / \mathrm{f}^{0.5} *$ & $\lambda=1.63 \mathrm{r} /(\mathrm{f})^{0.5}$. They proposed $\lambda$ (mean linear intercept) $/ 1.38=$ mean grain radius of a truncated octahedron. \\
\hline $\begin{array}{l}\text { Hazzledine et al. (1980): Ref. } \\
{[13]}\end{array}$ & $0.73-0.91 \mathrm{r} / \mathrm{f}^{*}$ & $\begin{array}{l}\text { Considered the effect of pulling of the grain boundaries by the particles causing 'dimples' on both sides of the grain surface }\left(P_{z}=1.1 \text { - }\right. \\
1.37 \gamma f / r\left(P_{B}=\gamma / R\right) \text {. }\end{array}$ \\
\hline $\begin{array}{l}\text { Hunderi and Ryum (1982): } \\
\text { Ref. [14] }\end{array}$ & $\begin{array}{l}0.67 \mathrm{r} / \mathrm{f} \text { or } \\
0.33 \mathrm{r} / \mathrm{f}\end{array}$ & $R_{c}=1 / 2 \mathrm{z}$ where $\mathrm{z}$ is either $3 \mathrm{f} / 4 \mathrm{r}$ or $3 \mathrm{f} / 2 \mathrm{r}$ (this was not clarified in the paper). \\
\hline Louat (1982): Ref. [15] & $4 r / 3 f\left\{16 /\left(\ln \left[\operatorname{Re}^{2} / 2 r\right]\right)\right\}$ & $\begin{array}{l}\text { Considered the effects of: a) particles at distances }>r \text { from the grain boundary, and b) some particles would assist the motion of the } \\
\text { grain boundaries. }\end{array}$ \\
\hline Doherty (1982): Ref. [16] & $0.17 \mathrm{r} / \mathrm{f}^{*}$ & $\begin{array}{l}\text { Considered the effect of coherent particles and arrived at } F_{z}=2 \pi r \gamma \text {, a value twice that given by Zener (but similar to Ashby et al. }{ }^{10)} \text { ). } \\
P_{z}=6 \gamma f / r \text { which is } 8 \text { times that suggested by Zener; }\left(P_{B}=\gamma / R\right) \text {. }\end{array}$ \\
\hline Ryum et al. (1983): Ref. [17] & $\begin{array}{l}\text { refer to text for equation } \\
\text { describing } F_{z}\end{array}$ & Considered the effect of ellipsoidal particles and their orientation with respect to the grain boundary on $\mathrm{F}_{\mathrm{z}}$. \\
\hline Srolovitz et al. (1984): Ref. [18] & $\begin{array}{l}A_{f}=3 a / f \\
R_{\varepsilon} \sim r / f^{0 . S}\end{array}$ & $A_{f}$ is the average grain area in the pinned state and $a$ is the area of the particle. The equation is a result of a 2-D computer simulation. \\
\hline $\begin{array}{l}\text { Chan and Humphreys (1984): } \\
\text { Ref. [19] }\end{array}$ & $1.45 r / t^{0.5} *$ & Considered the effect of ledge mechanism of grain boundary migration to arrive at an equation for $P_{z}\left(P_{g}=2 \gamma / R\right)$. \\
\hline Nes et al. (1985): Ref. [4] & $1.54 \pi / f^{0.92 *}$ & $\begin{array}{l}\text { Correction of original Zener's equation. They also considered the effect of initial distribution of grain size on } R_{c} \text {. Dimple model: } P_{z}= \\
1.3 \gamma f^{0.92} / \mathrm{r}\left(\mathrm{P}_{\mathrm{B}}=2 \gamma / \mathrm{R}\right) \text {. }\end{array}$ \\
\hline Rios (1987): Ref. [20] & $0.17 \mathrm{r} / \mathrm{f}$ & Considered an energy dissipation approach, rather than pinning pressure when a grain boundary moves through a dispersion of particles \\
\hline Doherty et al. (1987): Ref. [21] & $1.7 \mathrm{r} / \mathrm{f}^{0.5}$ & Result of a 2-D computer simulation considering a non-random particle distribution. \\
\hline Hillert (1988): Ref. [22] & $\begin{array}{l}0.22 \mathrm{r} / \mathrm{f}^{0.93} \\
1.8 \mathrm{r} / \mathrm{f}^{0.33} \\
1.7 \mathrm{r} / \mathrm{f}^{0.9}\end{array}$ & $\begin{array}{l}\text { 3-D calculation; } f<0.1 \\
\text { 3-D calculation; } f>0.1 \\
\text { 2-D calculation (attempts to explain computer simulation results by using mean field theory). }\end{array}$ \\
\hline Elst et al. (1988): Ref. [23] & $\begin{array}{l}2 / 3 \beta(3 / 2-2 / Z) r / f \cong \\
0.075-0.45 \mathrm{r} / \mathrm{f}\end{array}$ & $\begin{array}{l}\text { Combined the approaches of Zener }{ }^{1)} \text {, Ryum et al. }{ }^{17} \text {, Gladman }{ }^{3)} \text {, and Hellman-Hillert }{ }^{(1)} \text {. They also calculate } R_{c} \text { for elongated } \\
\text { precipitates, bimodal distribution, and grain boundary precipitates. }\end{array}$ \\
\hline $\begin{array}{l}\text { Anderson et al. (1989): Ref. } \\
\text { [24] }\end{array}$ & $4.5 \pm 0.8 \mathrm{r} / \mathrm{f}^{0.31 \pm 0.02}$ & Results of a 3-D Monte Carlo computer simulation. \\
\hline Ringer et al. (1989): Ref. [25] & $1 / 2 \mathrm{~K}(\mathrm{r} / \mathrm{f})$ & $\begin{array}{l}K \text { depends on interaction geometry of the boundary with the particle. (Assuming incoherent particles and } \rho=2.15 \mathrm{D}: \mathrm{i}) \mathrm{R}_{\mathrm{c}}=0.16 \mathrm{r} / \mathrm{f} \text { for } \\
\text { spherical particles, and ii) } R_{\mathrm{c}}=0.06 / 0.08 / 0.12 \mathrm{r} / \mathrm{f} \text { for cubic particles of different orientations with respect to the grain boundary). }\end{array}$ \\
\hline Hunderi et al. (1989): Ref. [26] & $6.1 \mathrm{r} / \mathrm{f}^{0.87} *$ for $\mathrm{f}<0.03$ & Considered Louat effect ${ }^{(5)}$ viz. some particles tend to assist grain boundary movement $\left(\mathrm{P}_{B}=2 \gamma / \mathrm{R}\right)$. \\
\hline $\begin{array}{l}\text { Hazzledine and Oldershaw } \\
\text { (1990): Ref. [27] }\end{array}$ & $\begin{array}{l}1.8 \mathrm{r} / \mathrm{f}^{05} \\
2 \mathrm{r} / \mathrm{f}^{.5} \\
R_{c} \propto r / f \\
R_{c} \propto r / f^{0.33}\end{array}$ & $\begin{array}{l}\text { Based on a 2-D computer simulation. } \\
\text { Proposed equation for particle-containing thin films, similar to above. } \\
\text { For } f<0.01 \text { (analytical result). } \\
\text { For } f>0.01 \text { (3-D computer simulation result). }\end{array}$ \\
\hline Gassold et al. (1990): Ref.[28] & $0.6 \mathrm{r} / \mathrm{f}^{0.55}$ & Result of a 2-D computer simulation, $f \leq 0.1$ \\
\hline $\begin{array}{l}\text { Patterson and Liu (1992): Ref. } \\
{[29,31]}\end{array}$ & $\begin{array}{l}\text { Theoretical: } 0.31 \mathrm{r} / \mathrm{f} \\
\text { Experimental: } 0.051 \text {. } \\
0.155 \mathrm{r} / \mathrm{f}\end{array}$ & $\begin{array}{l}\text { Considered the relationship between } \lambda \text { (Mean Linear Intercept) and the grain boundary curvature: } \rho=\lambda / 0.31, \lambda=1.33 \mathrm{R}, \mathrm{so} \rho=4.3 \mathrm{R} \text {. } \\
\text { Experimentally-determined values of } \mathrm{K} \text { lower than theoretical values due to a non-random intersection of pores with the grain } \\
\text { boundaries. Data for } \mathrm{Al}-\mathrm{Al}_{2} \mathrm{O}_{3} \text { system by Tweed et al. }{ }^{30} \text { fitted well with the proposed equation. }\end{array}$ \\
\hline Manohar et al. (1996): Ref.[32] & $0.17 \mathrm{r} / \mathrm{f}$ & $\begin{array}{l}\text { iction from the equation correlated well with the experimental data for the growth of mean austenite grain size during reheating of } \\
\text { b microalloyed steel slabs. }\end{array}$ \\
\hline
\end{tabular}


Table 2. (Continued)

\begin{tabular}{|c|c|c|}
\hline $\begin{array}{l}\text { Liu and Patterson (1996): Ref. } \\
\text { [33] }\end{array}$ & $\begin{array}{l}\lambda_{B}=k \lambda_{P} / R f \\
k \cong 0.31\end{array}$ & 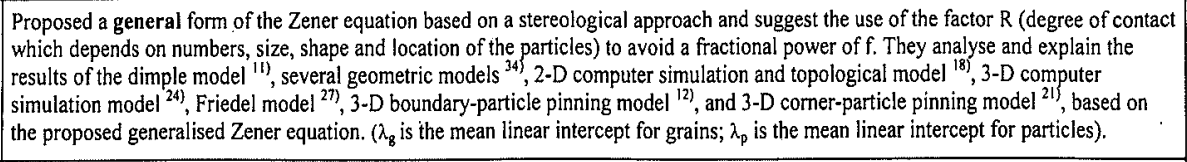 \\
\hline Rios (1996): Ref. [35] & $0.33 \mathrm{r} / \mathrm{f}$ & The proposed equation is based on three different approaches. \\
\hline Gao et al, (1997): Ref. [36] & $0.59 r / 9^{0.52}$ & $\begin{array}{l}\text { Result of a 2-D computer simulation by considering that the degree of contact between the grain boundaries and particles increases } \\
\text { during the process of grain growth and reaches a stable value when boundaries become pinned. }\end{array}$ \\
\hline Manohar (1997): Ref. [37] & $\begin{array}{l}0.23 \mathrm{r} /(\beta \mathrm{f})^{0.5} \\
\beta=\mathrm{a}_{\mathrm{d}} / 2 \pi \mathrm{R}_{0}\end{array}$ & $\begin{array}{l}\text { Prediction from the equation correlated well with the experimental data for grain growth of mean austenite grain size during reheating } \\
\text { of Ti-Nb MA steel in as-cast slab as well as controlled-rolled plate conditions. } a_{0} \text { is the size of cubic particle and } \beta \text { depends on the } \\
\text { relative sizes of the grains and particles. }\end{array}$ \\
\hline $\begin{array}{l}\text { Kad and Hazzledine (1997): } \\
\text { Ref. [38] }\end{array}$ & $\begin{array}{l}1.41 \mathrm{r} / \mathrm{f}^{0.5} \\
\mathrm{R}_{\mathrm{c}} \propto 1 / \mathrm{f}^{0.33}\end{array}$ & $\begin{array}{l}\text { Result of a 2-D Monte Carlo computer simulation based on a square and hexagonal lattice in the presence of a dispersion of specially- } \\
\text { shaped (sphere, needle, plate) particles. } \\
\text { Result of a 3-D Monte Carlo computer simulation based on a simple cubic and fcc lattice in the presence of a dispersion of specially- } \\
\text { shaped (sphere, needle, plate) particles. }\end{array}$ \\
\hline
\end{tabular}

* These equations have been derived ${ }^{37)}$ after equating the Zener pressure $\left(\mathrm{P}_{2}\right)$ with the appropriate expression for $\mathrm{P}_{8}$ as given under 'comments'.

modification results in a significantly lower value of $K$ $(=0.074)$ in Eq. (2).

It is clear from these additional studies that interface geometry, particle shape, grain shape and particle coherency have an influence on the form of Eq. (3).

\subsection{Consideration of Particle Distribution}

The following assumptions were made by Zener with respect to particle distribution:

- all particles are of equal size;

- particles are randomly distributed, and

- particles interact with only one grain boundary. Fullman ${ }^{5)}$ accounted for a range of particle size by introducing a 'dirt factor' $(I)$ which is given by $\sum f(r) / r$ where $f(r)$ is the volume fraction of monosized spherical particles of size $r$. The pinning pressure was given as:

$$
P_{\mathrm{z}}=3 \gamma I / 4
$$

The effect of non-random particle distribution was studied by Wold and Chambers ${ }^{9)}$ who argued that particles form preferentially at the grain boundaries and derived the following equation:

$$
P_{\mathrm{z}}=3 k \gamma f / 4 r
$$

where $k$ is a factor greater than unity which expresses the greater likelihood of finding particles on the grain boundary than in the grain interior.

Hunderi and Ryum ${ }^{39)}$ argued that the assumption of particles interacting with only one grain boundary is incorrect, particularly in materials with a high volume fraction of particles $(f>0.1)$ such as particulate reinforced metal-matrix composites (PMMCs) and superplastic materials. They suggested that, for large volume fractions, some particles will interact simultaneously with three grain boundaries meeting along triple lines or with six grain boundaries meeting at quadruple points. They derived an equation for $R_{\mathrm{c}}$ by assuming that the total fraction of particles at different positions will depend on constants $\alpha$ and $\beta$, and the parameters $r$, $f$ and $R$ such that:

$$
R_{\mathrm{c}}=8 r / 9 f\left[2 \alpha f+0.25+\sqrt{(2 \alpha f+0.25)^{2}+15 f^{2} \beta}\right] \ldots
$$

The condition $\alpha=\beta=1$ indicates that restraining force from the particles in triple lines and quadruple points is zero while the condition $\alpha=\beta=0$ occurs when all particles interact with equal force.

Hazzledine et al. ${ }^{13)}$ proposed that the attraction of the flexible grain boundary by many particles causes dimples on both the inner and the outer surface of the boundary and found:

$$
P_{\mathrm{z}}=1.1-1.37 \gamma \mathrm{f} / \mathrm{r}
$$

Equation (14) is close to the modified Zener estimate of $1.5 \gamma f / r$ (Eq. (5b)). A similar result was obtained by Nes et al. ${ }^{4)}$ viz.:

$$
P_{z}=1.3 \gamma f^{0.92} / r \cong 1.3 \gamma f / r
$$

Louat ${ }^{15)}$ proposed that particles ahead of a moving grain boundary attract the boundary and assist its movement resulting in particle-assisted grain boundary movement. In addition, the effect of particles which trail the boundary at distances exceeding $r$ was also considered to arrive at:

$$
R_{\mathrm{c}}=4 r / 3 f\left\{16 / \ln \left(\operatorname{Re}^{2} / 2 r\right)\right\}
$$

This result indicates that for large $R$ values, $R_{\mathrm{c}}$ would be smaller than the Zener equation (i.e. higher restraint) and for small $R$ values, $R_{\mathrm{c}}$ would be larger (i.e. less restraint).

Hunderi et al. ${ }^{26)}$ incorporated the Louat effect ${ }^{15)}$ in their model which can be given as:

$$
P_{\mathrm{z}}=0.33 \gamma f^{0.87} / r \text { for } f<0.03
$$

The effect of the mechanism of grain boundary migration on $P_{z}$ was considered by Chan and Humphreys ${ }^{19)}$ where it was proposed that grain boundaries may migrate by means of ledges or steps sweeping across the boundary (surfaces of the grain boundaries are not atomically smooth), suggested that $P_{\mathrm{z}}$ for Orowan spacing of particles may be calculated as:

$$
P_{\mathrm{z}}=1.38 \gamma f^{0.5} / r
$$

which results in a pinning pressure almost an order of magnitude larger than Eq. (5b).

The effect of grain size on $P_{z}$ was first considered by Hellman and Hillert ${ }^{11}$ who suggested that as a grain increases in size, the grain boundary is able to stay in contact with particles over a longer distance thereby 
increasing the pinning effect that is proportional to $\rho / r$, where $\rho(=6 R)$ is the macroscopic curvature of the grain boundary. They found that:

$$
R_{\mathrm{c}}=4 r / 9 \beta f
$$

where $\beta$ is either (i) $0.125 \ln (8 \rho / r)$ or (ii) $0.125 \ln (40 \rho / r)$, the latter expression being closer to numerical calculations. It is clear from Eq. (19) that the ratio $\rho / r$ controls the value of $R_{\mathrm{c}}$. Considering (i) for $\rho / r=10, R_{\mathrm{c}}=$ $0.59 r / f$ while for $\rho / r=10^{4}, R_{\mathrm{c}}=0.28 r / f$. This result is in qualitative agreement with Louat ${ }^{15)}$ although based on a completely different concept. Stearns and Harmer ${ }^{40}$ ) also considered the effect of grain size on $P_{z}$ but proposed that, as grain size increases, while the fraction of particles on the grain boundary $(\phi)$ decreases, the number of particles per unit area of grain boundary $\left(n_{\mathrm{s}}\right)$ increases, thereby resulting in a much smaller predicted grain size according to:

$$
R_{\mathrm{c}}=\left(4.8 \beta r^{2} / f \varepsilon\right)^{1 /(2-x)}
$$

where $\beta=20.4, \varepsilon=1.88 \times 10^{-4}\left(\mathrm{~m}^{0.6}\right)$ and $x=0.6$.

Using a simplified lattice model, Humphreys and Hatherly ${ }^{41)}$ showed that pinning pressure is affected by both grain size and particle spacing. For a grain size less than the particle spacing, it was shown that, as grain size increases, the pinning pressure rises according to:

$$
P_{\mathrm{z}}=3 \gamma f / 4 r^{2}
$$

When the grain size reaches the particle spacing, the pinning pressure was found to be a maximum $\left(R=R_{\mathrm{c}}\right)$ :

$$
P_{\mathrm{z} \max }=1.2 \gamma f^{0.67 / r}
$$

A further increase in grain size beyond $R_{\mathrm{c}}$ resulted in a decrease in the pinning pressure to the value given by Eq. (5b).

\subsection{The Relationship between Boundary Curvature $(\rho)$ and Grain Radius $(R)$}

In Zener's original derivation, the driving pressure for grain growth $\left(P_{\mathrm{g}}\right)$ was given as $\gamma / \rho_{\text {net }}$ where $\rho_{\text {net }}=\rho / 2$ and $\rho$ is the macroscopic curvature of a spherical grain. Thus the driving pressure for grain growth $\left(P_{\mathrm{g}}\right)$ is $2 \gamma / \rho$, which when related to grain radius $(R)$ gives $P_{\mathrm{g}}=\gamma / R($ Eq. $(7 \mathrm{f}))$.

Feltham ${ }^{42}$ analysed the relationship between the radius of curvature and the shape of a grain in two dimensions and arrived at:

$$
R / \rho=\sin \left[\pi / 6\left(1-n^{*} / n\right)\right] / \sin \left[\pi / 6\left(n^{*} / n\right)\right]
$$

where $n$ is the number of sides of a grain and $n^{*}$ the most probable number of sides of a grain to be expected in a truly planar arrangement $(=6)$. This equation demonstrates that a grain with less than six sides has convex boundaries and will shrink, whereas a grain with more than six sides has concave boundaries and will grow. Other values of $\rho$ were suggested by Haroun and Budworth $^{8)}(\rho=18 R)$ and Hellman and Hillert ${ }^{11)}$ $(\rho=6 R)$. Patterson and $\mathrm{Liu}^{29)}$ incorporated a metallographic parameter 'mean linear intercept' $(\lambda)$ in their analysis and derived the relation $\lambda=0.31 \rho$ for a three dimensional aggregate of grains. Using the relation $\hat{\lambda}=1.33 R$ reported by $\mathrm{Han}$ and $\mathrm{Kim}^{43)}$ for spherical grains, the value of $\rho$ thus becomes $\rho=4.3 R$. It is clear that these approaches give a much smaller value of $P_{\mathrm{g}}$ than that proposed by Zener, a result which strongly affects $R_{\mathrm{c}}$.

\subsection{Consideration of Initial Grain Size Distribution}

The original derivation of the Zener equation did not involve any consideration of the effect of initial grain size distribution on $P_{\mathrm{g}}$. Hillert ${ }^{6)}$ analysed the effect of grain size distribution together with the pinning effect of particles on the overall process of grain growth and found two limiting values:

$$
R_{\mathrm{c} 1}=0.44 \mathrm{r} / \mathrm{f}
$$

where $R_{\mathrm{c} 1}$ is the limit for normal grain growth. However, abnormal grain growth may then occur until a second limit is reached:

$$
R_{\mathrm{c} 2}=0.67 \mathrm{r} / \mathrm{f}
$$

where $R_{\mathrm{c} 2}$ is the limit for total grain growth inhibition.

Gladman $^{3,7)}$ analysed the effect of grain size distribution on the driving pressure (and therefore $R_{\mathrm{c}}$ ) and found that:

$$
R_{\mathrm{c}}=r / f[\pi(0.25-0.33 / Z)]
$$

where $Z$ is the ratio of growing grains to matrix grains and thus represents the heterogeneity of grain size distribution in the sample. Equation (24) indicates that an increase in $Z$ will result in a greater tendency for grains to coarsen, that is, a larger limiting diameter.

Using Gladman's model, Wold and Chambers ${ }^{9)}$ introduced a factor ' $k$ ' $(1<k<2)$ and showed that:

$$
R_{\mathrm{c}}=2 r / 3 k f[(3 Z-4) / 2 Z]
$$

which demonstrates both the effect of non-random distribution of particles and the heterogeneity of grain size distribution on $R_{\mathrm{c}}$.

The effect of mobile particles on grain boundary motion was studied by Gottstein and Shvindlerman ${ }^{44)}$ by introducing a dimensionless parameter $\beta$ to explain the phenomenon:

$$
\beta=\int_{0}^{\infty} \bar{n}(r) m_{\mathrm{b}} / m_{\mathrm{p}}(r) d r
$$

It was proposed that for $\beta \ll 1$ (small particles) boundary motion is controlled by boundary mobility $\left[m_{\mathrm{b}}\right]$, but for $\beta \gg 1$ (large particles), boundary velocity is determined by particle density $[\bar{n}(r)]$ and particle mobility $\left[m_{\mathrm{p}}(r)\right]$. This theory qualitatively accounts for the experimental fact that the actual grain size in the pinned state is much smaller than that predicted because particle coarsening leads to a decrease in particle mobility which subsequently decreases the velocity of grain boundary migration.

\section{Applications of the Zener Equation}

The Zener equation has been utilised for fifty years to provide both a theoretical explanation of grain growth and to model other annealing phenomena in particlecontaining materials. Some typical examples of applica- 
tions of the equation to recovery, recrystallization and grain growth are given in the following sections.

\subsection{Recovery}

Second-phase particles may affect both static and dynamic recovery by either (i) pinning individual dislocations and so restricting the initial formation of low angle boundaries, or (ii) restricting the growth of subgrains. While no sound theories of boundary mobility based on dislocation interactions have been formulated, reasonable progress has been made on the effect of particles on subgrain growth. Jones and Hansen ${ }^{45}$ demonstrated, in aluminium containing a fine dispersion of $\mathrm{Al}_{2} \mathrm{O}_{3}$ particles, that pinning of low angle grain boundaries and dislocations can strongly influence the recovery process. It was also shown that secondary events such as interaction of particles and dislocations retard the rate of recovery in addition to the Zener pinning effect. Using a range of plain carbon steels, Anand and Gurland ${ }^{12)}$ obtained a good correlation between subgrain size and the size of spheroidized cementite particles, and showed that the limiting subgrain size was consistent with an $f^{-1 / 2}$ relationship. Chang ${ }^{46)}$ studied the subgrain growth in a particle-containing $\mathrm{Al}-\mathrm{Cu}$ alloy where TEM observations of $\theta$ particles revealed that almost all particles lie on subgrain boundaries. Subgrain growth was found to be stagnated when the dispersion parameter ( $f / r)$ was greater than $0.25 \mu \mathrm{m}^{-1}$, a limit well below that given by Eq. (1). It was concluded that subgrain growth was more strongly inhibited by a non-random distribution of particles.

\subsection{Recrystallization}

Second-phase particles may also impede both nucleation and the subsequent growth of recrystallized grains. The net driving pressure for recrystallization $(P)$ may be determined from a balance of driving pressure for growth $\left(P_{\mathrm{D}}\right)$ with both the Zener pinning pressure $\left(P_{\mathrm{z}}\right)$ and (for the early stages of growth) the retarding pressure due to boundary curvature $\left(P_{\mathrm{C}}\right)^{41)}$ :

$$
P=P_{\mathrm{D}}-P_{\mathrm{z}}-P_{\mathrm{C}}=\alpha \Delta \rho G \mathbf{b}^{2}-3 f \gamma / 2 r-2 \gamma / R
$$

where $G$ is the shear modulus, $\mathbf{b}$ is the Burgers vector, $R$ is subgrain (nucleus) radius and $\Delta \rho$ is the change in dislocation density associated with the migration of the recrystallization front into the deformation substructure. It is clear from Eq. (27) that a recrystallized grain can not grow unless $P$ is positive and the progress of recrystallization will be critically dependent on the value of the dispersion parameter $(f / r)$. Humphreys and Hatherly ${ }^{41}$ have shown that nucleation will be suppressed when $f / r>0.15 \mu \mathrm{m}^{-1}$, a value which is in reasonable agreement with experimental observations. The growth of a recrystallization nucleus is impeded for values of $f / r$ between 0.2 and $0.6 \mu \mathrm{m}^{-1}$ which is consistent with particle-inhibition of nucleation. ${ }^{19)}$ It was concluded that Zener pinning plays a major role in retarding primary recrystallization by affecting both nucleation and growth of grains. The use of the balance of pressures (as in Eq. (27)) has important implications in the control of grain size and texture of many industrially-significant alloys (Sec. 5).

The influence of $f / r$ on recrystallization kinetics was experimentally demonstrated first by Doherty and Martin ${ }^{47)}$ in a range of $\mathrm{Al}-\mathrm{Cu}$ alloys where it was shown that the rates of both nucleation and growth of grains during recrystallization were greatly dependent on $\mathrm{f} / \mathrm{r}$. The mathematical treatment which predicted the recrystallization kinetics in the presence of a dispersion of particles was developed by Nes. ${ }^{48)}$ The model successfully accounted for the recrystallization kinetics of a cold-deformed Al-Mn alloy, and has been used to account for the recrystallization kinetics of other colddeformed Al-alloys. ${ }^{49,50)}$ It was shown by Nes that the effect of large particles and small, finely dispersed particles on recrystallization was significantly different. Small, finely dispersed particles (small $f / r$ ) pin the potential nuclei and decrease the nucleation rate. The formation of a viable nucleus must be accomplished prior to the stage where subgrain growth has caused the growth of the average subgrain size to a value equal to $4 \alpha r / 3 f(\alpha \sim 1)$; at this stage the nucleation is completely inhibited. On the other hand, large particles (large $f / r$ ) act as nucleation sites and promote nucleation rate. A particle size of $\sim 0.5-1.0 \mu \mathrm{m}$ was considered the minimum critical size for particle to act as a nucleation site. This theory was developed further by Humphreys $^{51-53)}$ who showed that the deformation zones that form around coarse $(>1 \mu \mathrm{m})$, non-deformable particles facilitate the formation of recrystallized nuclei by particle stimulated nucleation (PSN). The critical particle size $\left(\eta_{\mathrm{c}}\right)$ for the growth of a nucleus was found to be:

$$
\eta_{\mathrm{c}}=2 \gamma /\left(P_{\mathrm{D}}-P_{\mathrm{z}}\right)
$$

Thus, the competition between nucleation in the vicinity of coarse particles and the pinning effect of fine particles results in a critical particle size for nucleation, and, as the Zener pinning pressure increases, the critical particle diameter for PSN increases.

The balance of pinning and driving pressure for recrystallization is currently being applied by some workers $^{54,55)}$ to study the hot deformation behaviour of microalloyed steels. It is suggested that inhibition of recrystallization would occur when the pinning pressure generated by precipitate particles on austenite grain boundary exceeds the driving pressure for recrystallization. Palmiere et al. ${ }^{55)}$ successfully predicted the recrystallization-stop temperature in one of their steels based on this approach. The recrystallization and precipitation in microalloyed steels, which may be sequential or simultaneous, occurs during thermomechanical processing and the nature and kinetics of these reactions depend not only on material composition, but also on the processing variables $(\dot{\varepsilon}, \varepsilon, T$, interpass time). On the other hand, recrystallization theory cited here relates to the sequential recrystallization phenomenon during isothermal treatment following the cold deformation of materials. Therefore, application of such recrystallization models to thermomechanical processing of microalloyed steels is a more difficult problem and needs further development. 


\subsection{Normal and Abnormal Grain Growth}

The Zener equation has been utilised most extensively to describe grain growth in particle containing materials (see Table 2), and the correlation between experimental results and prediction in a wide range of materials has been found to be encouraging. For example, Palma et $a l .{ }^{56)}$ found the equation useful in predicting grain size in sintered high speed tool steel while Hellman and Hillert ${ }^{11)}$ used the equation to explain grain growth of ferrite in the presence of cementite particles. Several workers have utilised the Zener approach to calculate the limiting grain size in $\mathrm{C}-\mathrm{Mn}$ steels ${ }^{57)}$ and in $\mathrm{C}-\mathrm{Mn}$ steels containing $\mathrm{Al} / \mathrm{Nb} / \mathrm{Ti}^{58)} \mathrm{Ti}^{59)}$ and $\mathrm{Nb}^{32.37)}$ and Al additions. ${ }^{60)}$ Grain growth behaviour has also been studied in a wide range of other particle-containing materials such as $\mathrm{Al}-\mathrm{Al}_{2} \mathrm{O}_{3}$ alloys, ${ }^{30)} \mathrm{Al}-\mathrm{Si}$ alloys, ${ }^{19)}$ copper-based shape memory alloys, ${ }^{23)}$ a Ni-base superalloy containing carbides, ${ }^{61)}$ two-phase $\mathrm{Ti}$ alloys ${ }^{62)}$ and a range of ceramic materials. ${ }^{63}$

The way in which the particles and the grain size distribution parameters interact to determine both normal and abnormal grain growth was demonstrated by Gladman ${ }^{3)}$ who suggested that when a boundary is unpinned, the energy of the system is increased. This increase in energy has to be balanced by the decrease in energy due to grain growth which leads to the following condition:

$$
r_{\text {crit }}=6 R_{\mathrm{o}} f / \pi(3 / 2-2 / Z)^{-1}
$$

where $r_{\text {crit }}$ is the critical particle radius for unpinning, $Z$ is a heterogeneity ratio $\left(R_{\max } / R_{\text {mean }}\right)$. This equation shows that when particles coarsen to $r_{\text {crit }}$, they can no longer pin the grains and grain growth can then proceed. $r_{\text {crit }}$ increases with increasing matrix grain size $\left(R_{0}\right)$ and volume fraction of particles $(f)$ and with decreasing $Z$. An increase in $r_{\text {crit }}$ will increase the grain coarsening temperature (GCT) because the particles must grow to $r_{\text {crit }}$ before grain growth can commence. On the other hand, for a material with a highly heterogeneous grain size distribution (high $Z$ ), even very fine particles are relatively ineffective in pinning grain boundaries because $r_{\text {crit }}$ decreases with increasing $Z$. Thus Gladman's theory indicates the possibility of a higher GCT (i.e. higher $r_{\text {crit }}$ ) if a material (i) has a relatively coarse matrix or mean grain size (higher $R_{\mathrm{o}}$ ), (ii) contains a high volume fraction of precipitates and (iii) has a lower heterogeneity in the grain size distribution (low Z). Gladman ${ }^{64)}$ also considered the effect of a non-random particle distribution on $r_{\text {crit }}$, and found:

$$
r_{\text {crit }}=2 R_{0} f^{0.5}(3 / 2-2 / Z)^{-1}
$$

Several workers ${ }^{7.64-74)}$ have since demonstrated that the GCT of microalloyed steels is a strong function of size, distribution, volume fraction and stability of microalloy precipitates.

\section{Incorporation of the Zener Factor in Theories of Annealing}

The Zener factor $(z=3 f / 4 r)$ is common to many theories of annealing in particle-containing materials, and has therefore made a profound impact in the studies of annealing.

\subsection{Kinetics of Normal and Abnormal Grain Growth}

Most theories for predicting the kinetics of grain growth and grain size distribution have incorporated the Zener pressure into the basic kinetic relation:

$$
v=M P
$$

where $v$ is the velocity of boundary migration in response to the net pressure $P$ on the boundary and $M$ is the mobility of the boundary. In a model proposed by Hillert, ${ }^{6)}$ the Zener factor was used to determine the kinetics of grain growth in particle-containing materials. The rate of grain growth $(v=d R / d t)$ was given as:

$$
\frac{d R}{d t}=\alpha M \gamma\left(1 / R_{\mathrm{cr}}-1 / R \pm z / \alpha\right)
$$

where $\alpha$ is a geometric constant of the order unity in a 3-D analysis and $R_{\mathrm{cr}}$ is the critical minimum grain radius for grain growth. As the pinning pressure $\left(P_{z}=\gamma z\right)$ always opposes the movement of the grain boundary, the rate of growth of the mean grain size is:

$$
\frac{d \bar{R}^{2}}{d t}=0.5 \alpha M \gamma(1-z \bar{R} / \alpha)^{2}
$$

An analytical model to predict the growth kinetics of abnormal grains was developed by Anderson et al. ${ }^{75)}$ according to:

$$
\frac{d \bar{R}_{\mathrm{ab}}}{d t}=M \gamma\left[\frac{1}{\bar{R}_{\mathrm{ab}} \tan \left(\frac{\Omega \bar{R}}{2 \bar{R}_{\mathrm{ab}}}\right)}-\frac{\sqrt{3}}{\bar{R}_{\mathrm{ab}}}-\frac{c^{\prime}}{2 \bar{R}_{\mathrm{lim}}}\right] \ldots
$$

where $\bar{R}_{\mathrm{ab}}$ is the radius of abnormal grain, $\bar{R}$ is the radius of matrix grain, $\Omega$ is a parameter which relates the grain boundary segment to the grain radius $\Omega=\frac{\pi}{2}-\frac{\pi}{6}\left(\frac{\bar{R}}{\bar{R}_{\mathrm{ab}}}\right)^{2}, c^{\prime}$ is parameter which relates $\bar{R}$ to the radius of curvature $(\rho)$ for a spherical grain, $\bar{R}_{\text {lim }}$ is the limiting grain size $(=k r / f)$. The model considers the dynamic events which occur during the overall process of grain growth i.e. when $\bar{R}, \bar{R}_{\mathrm{ab}}$ and $\bar{R}_{\mathrm{lim}}$ increase with time and temperature. The important aspect here is to find the rate of growth of each relative to others which determines the nature (normal or abnormal) of grain growth. The solution of Eq. (34) was suggested to be the general criterion for initiation of abnormal grain growth in terms of the ratios $\bar{R}_{\mathrm{ab}} / \bar{R}$ and $\bar{R} / \bar{R}_{\text {lim }}$. The model explains qualitatively the experimentally observed phenomenon of grain coarsening temperature (GCT) in microalloyed steels and also supports the predictions based on classical grain growth theories. ${ }^{3.7)}$ A similar approach has been proposed by Rios ${ }^{76-78)}$ to predict the onset and termination of abnormal grain growth by calculating relative rates of growth of $\bar{R}, \bar{R}_{\mathrm{ab}}$ and $R_{\mathrm{c}}$. The applicability of this model to explain the normal and abnormal grain growth during reheating of microalloyed austenite has been discussed in detail by Manohar and Chandra ${ }^{79)}$ where it was shown that the 
model could be used to calculate the GCT in microalloyed steels. However, full potential of this model could be realised when appropriate models are developed to determine the volume fraction and the growth rate of abnormal grains.

In a recently proposed unified theory of recovery, recrystallization and grain growth in particle-containing cellular microstructures, Humphreys ${ }^{80.81)}$ utilised Eq. (31) to determine the growth rate of a 'particular' grain of radius $R$ with respect to an assembly of equiaxed grains of mean radius $\bar{R}$ such that:

$$
\begin{gathered}
\frac{d R}{d t}=M\left(\bar{\gamma} / \bar{R}-\gamma / R-Z_{\mathrm{H}} \gamma / \bar{R}\right) \\
\frac{d \bar{R}}{d t}=\bar{M} \bar{\gamma} / \bar{R}\left(1 / 4-Z_{\mathrm{H}}\right) . .
\end{gathered}
$$

where $\bar{M}$ and $\bar{\gamma}$ are the mean mobility and energy of an assembly of grains, $M$ and $\gamma$ are the mobility and energy of a 'particular' grain and $Z_{\mathrm{H}}$ is a dimensionless parameter incorporating the Zener factor (Eq. (6b)):

$$
Z_{\mathbf{H}}=\frac{3 f \bar{R}}{2 r}
$$

It was suggested that a given softening phenomenon may or may not occur depending on the value of the parameter $\left(Z_{\mathbf{H}}\right)$ :

$Z_{\mathrm{H}}=0$ $0<Z_{\mathrm{H}}<0.1$

Normal grain growth.

Broadening of the grain size distribution.

$0.1<Z_{\mathrm{H}}<0.25$ Normal and abnormal grain growth.

$0.2<Z_{\mathrm{H}}<1 \quad$ Abnormal grain growth but no normal grain growth.

$Z_{\mathrm{H}}>1 \quad$ No grain growth.

\subsection{Recrystallized Grain Size}

The Zener pressure has also been used to model the recrystallization kinetics and to predict recrystallized grain size and texture in particle-containing materials. Several workers ${ }^{48.82-84)}$ have utilised the balance of driving pressure and pinning force (Eq. (27)) to determine the critical diameter for growth of a recrystallization nucleus and hence predict the recrystallized grain size. Given that the number of successful nuclei per unit volume can be calculated, the recrystallised grain diameter $\left(D_{\mathrm{R}}\right)$ for site saturated nucleation may be predicted by:

$$
D_{\mathrm{R}(\mathrm{SS})}=\left[N_{\mathrm{v}}\left(\eta_{\mathrm{C}}\right)\right]^{-1 / 3}
$$

Wert and Austin ${ }^{85)}$ showed for Johnson-Mehl kinetics that the recrystallized grain size $\left(D_{\mathrm{R}}\right)$ in bimodal alloys is given by:

$$
D_{\mathrm{R}(\mathrm{JM})}=K\left[\left(P_{\mathrm{D}}-P_{\mathrm{z}}\right) / N_{\mathrm{v}}\left(\eta_{\mathrm{C}}\right)\right]^{1 / 4}
$$

where $N_{\mathrm{v}}\left(\eta_{\mathrm{C}}\right)$ is the number of particles greater than a critical diameter for PSN and $K$ is an experimental constant incorporating nucleation frequency and mobility factors. The model accurately predicted the variation of recrystallized grain size with strain for alloys containing a wide range of particle dispersions and has been used to predict the recrystallized grain size in aluminium alloys suitable for use in superplastic applications. Nes and Hutchinson ${ }^{86)}$ have reviewed the effect of Zener pinning on the mode and kinetics of recrystallization which determine the final grain size and texture during industrial processing of aluminium, copper and low carbon steel sheets. A series of processing maps were developed which related the recrystallized grain size during industrial processing to the particle dispersion $(f / r)$.

\section{Discussion}

\subsection{Modifications to the Zener Equation}

It has been shown in Sec. 3 that many modifications have been made in an attempt to make the equation more practical in predicting the limiting grain size in real materials (see Table 2). These modifications have resulted in an equation of the general form $R_{\mathrm{c}}=K r / f^{m}$ (Eq. (2)). It was shown that the pinning force due to a single particle $\left(F_{z}\right)$ could be either lower or higher than the original estimate depending on the position of the grain boundary with respect to the particle, coherency and shape of the particle. In addition, it was also shown that the particle density $\left(n_{\mathrm{s}}\right)$ was higher, pinning pressure due to all particles on the grain boundary $\left(P_{z}\right)$ much higher and the driving pressure for grain growth $\left(P_{\mathrm{g}}\right)$ lower compared to the original estimate; the overall effect is a finer predicted limiting grain size than that given by Eq. (1). The maximum pinning (drag) pressure $\left(P_{z}\right)$ has been found by several researchers ${ }^{10,19,25)}$ to be considerably higher than the Zener estimate. Values of $P_{z}$ slightly higher than the original estimate (Eq. (5a)), but closer to the modified estimate given by Eq. (5b) were reported by Nes et $a .^{4)}$ and Hazzledine et $a l .^{13)}$ On the other hand, the approaches by Louat, ${ }^{15)}$ Hellman and Hillert ${ }^{11)}$ and Worner and Hazzledine ${ }^{63)}$ showed that $P_{z}$ also depended on the ratio $\rho / r$. It was found that $P_{\mathrm{z}}$ was lower than the Zener estimate when $\rho / r$ was low but was higher for larger values of $\rho / r$. In our view, the use of the factor $\rho / r$ is important because it can accommodate different initial microstructures and particle sizes and thus allows an estimation of the effects of these variables on $P_{z}$. In a model recently developed by Manohar, ${ }^{37)}$ the effectiveness of this approach was demonstrated by adequately predicting the limiting grain radius during reheating of a range of microalloyed steels.

The driving pressure for grain growth $\left(P_{\mathrm{g}}\right)$ was originally suggested ${ }^{1)}$ to be $\gamma / R$ (Eq. (5c)) while later researches have found that this value is a considerable overestimation. For example, values of $P_{\mathrm{g}}$ have been suggested to be: (i) 8.5 to $50 \%$ by Gladman ${ }^{3)}$ (depending on $Z$ ), (ii) $23 \%$ by Liu and Patterson ${ }^{31}$ based on experimental observations, (iii) $5.5 \%$ by Haroun and Budworth $^{8}$ and (iv) $18 \%$ by Hellman and Hillert ${ }^{11}$ of the original estimate. The value of $P_{\mathrm{g}}$ depends on the assumptions concerning shape, geometry and dimensionality of the grain structure and it is difficult to assess the validity of each assumption. In view of the comparable results reported by several investigators, ${ }^{6.11 .13}$ ) $\rho \sim 4 R$ therefore seems to be the most reasonable choice 


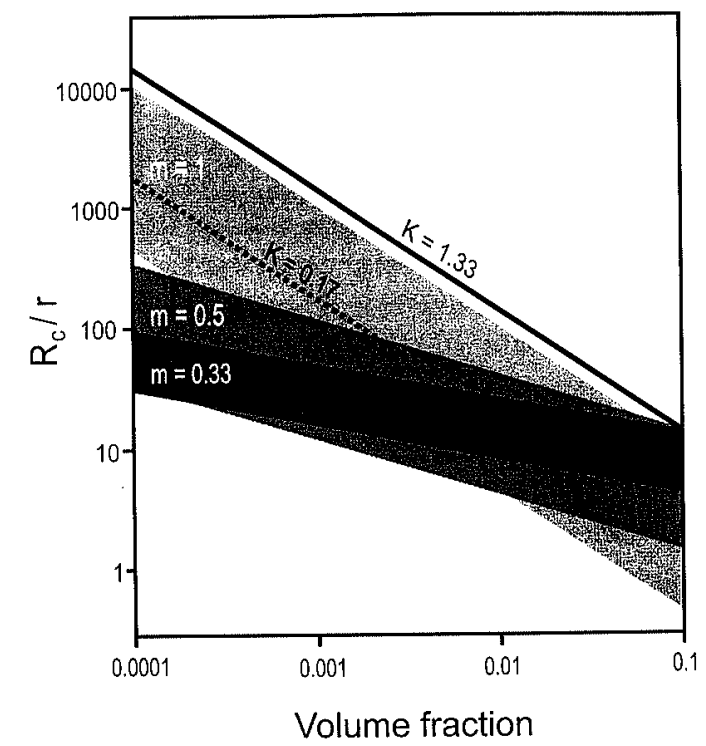

Fig. 2. Ratio of the limiting grain radius to particle radius $\left(R_{\mathrm{c}} / r\right)$ as a function of volume fraction of particles $(f)$. The equations for $R_{\mathrm{c}}$ listed in Table 2 are grouped into three bands for the exponents $m=0.33,0.5$ and 1.0 .

which results in $P_{\mathrm{g}}$ of about $25 \%$ of the original estimate.

With reference to Table 2, some further observations can be made regarding the modifications to Eq. (1) such as the variation in the values of $K$ and $m$. In all cases where $m=1, K$ is significantly lower than that given by Zener, and a lower value of $R_{\mathrm{c}}$ is therefore predicted. Furthermore, for all modifications, whether derived analytically or determined experimentally, the exponent for $f$ lies in the range $0.3<m<1.0$, and so depending on the values of both $K$ and $m$, a range of values for $R_{\mathrm{c}}$ is predicted. Figure 2 shows the effect of volume fraction of particles on the limiting grain radius for the majority of the equations listed in Table 2. It can be seen that the results are grouped into three bands depending on the value of $m(0.33 \pm 0.1,0.5 \pm 0.1$ and 1.0). Figure 2 also shows that, for the range of particle volume fractions commonly found in engineering materials $\left(f=10^{-4}\right.$ $10^{-2}$ ), values of $R_{\mathrm{c}}$ (for $m=0.33$ ) fall within the band $m=0.5$, and that all bands overlap in this range for $f$. Clearly, the Zener limit provides an upper limit for predictions of $R_{\mathrm{c}}$ but for high volume fractions $(f>0.1)$, equations with $m$-values in the range $0.3-0.5$ approach this limit. The dashed line in Fig. 2 shows the limiting grain radius for $K=0.17$ and $m=1$, which are values close to those given by a number of equations in Table $2.3,7,16,20,31,32,57)$ Experimental grain growth data in a variety of material systems are presented in Fig. 3. It is clear from Fig. 3 that a number of data closely follow the line for $K=0.17$ and $m=1.0$, particularly at lower volume fractions. This suggests that for material systems where $f$ is less than $0.05, K=0.17$ and $m=1.0$ is a reasonable choice. This is not surprising if one considers that the pinning pressure has been suggested to be twice while the driving pressure a quarter of the Zener estimate as discussed above. The overall effect of these modifications is that they result in $K$ which is an eighth of that given by Zener (1.33) which leads to $K=0.17$. On the other hand, in high volume fraction materials

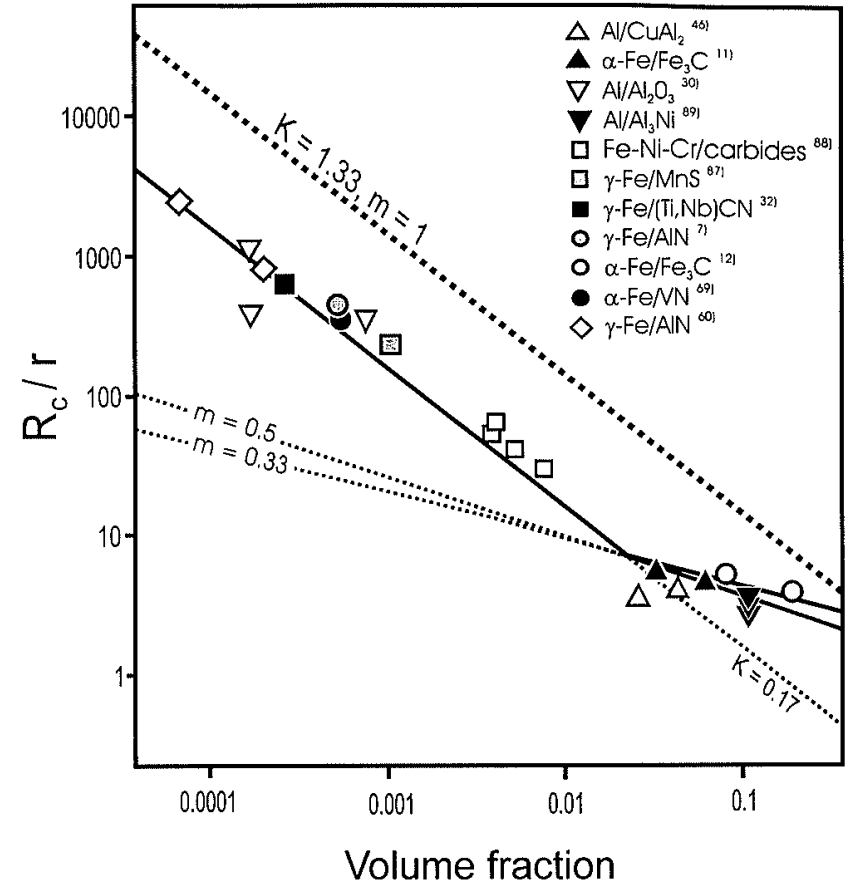

Fig. 3. Experimental data of ratio of limiting grain radius to particle radius $\left(R_{\mathrm{c}} / r\right)$, as a function of volume fraction of particles $(f)$. For $f<0.05$, the data fall close to the line for $K=0.17$ and $m=1$. The data follows more closely a $m \leq 0.5$ relationship for $f>0.05$.

$(f>0.05)$, the data points follow the line for weaker dependence on volume fraction (i.e. $m \leq 0.5$ ). This observation compares well with the computer simulation results obtained by Hazzledine and Oldershaw ${ }^{27)}$ which shows a discontinuity in the $R_{\mathrm{c}} / r v / s f$ curve at $f>0.01$. It has been suggested ${ }^{27,89)}$ that for $f>0.05$ the nonrandom correlation of boundaries with particles becomes more significant leading to a deviation from $f^{-1}$ to $f^{-1 / 3}$ dependency of $R_{\mathrm{c}}$.

\subsection{Future Considerations}

If it is assumed that the current analytical models and experimental data provide us with sufficient information on grain growth in particle-containing materials, an integrated global model for the Zener equation may be formulated. The aim of such a model is to account for the majority of the modifications and then to predict the limiting grain size $\left(R_{\mathrm{c}}\right)$ as a function of material, microstructure and processing variables. Considering the complexity of such a model, it is likely to be based on artificial intelligence (AI) techniques utilising knowledgebases and mathematical modelling. Such a model may be represented in the general form:

$$
\begin{aligned}
& R_{\mathrm{c}}=\frac{r}{f^{m}} . \\
& \quad\left[f_{1}(T) \cdot f_{2}\left(C_{\mathrm{o}}\right) \cdot f_{3}(\theta, \gamma) \cdot f_{4}\left(\bar{R}_{\max } / \bar{R}\right) \cdot f_{5}(\rho) \cdot f_{6}(\phi) \cdot f_{7}(\varphi)\right]
\end{aligned}
$$

where $T$ is absolute temperature, $C_{0}$ is matrix composition, $f_{3}(\theta, \gamma)$ is a parameter taking into account the misorientation and energy of grain boundaries, $f_{4}\left(\bar{R}_{\text {max }} / \bar{R}\right)$ is a parameter which represents heterogeneity in the initial microstructure, $f_{5}(\rho)$ and $f_{6}(\phi)$ are parame- 
ters defining shape and distribution of grains and particles respectively, and $f_{7}(\varphi)$ is a parameter describing the interaction geometry of a grain boundary and particles.

The input parameters would describe the material composition $\left(C_{\mathrm{o}}\right)$, initial microstructure $\left(\bar{R}_{\max }, \bar{R}\right.$, shape, size, type and distribution of particles) and processing parameters $(T, t)$. The output of such a computer program will depend on the intelligent choices the program makes to suit the given input parameters. The precise nature of the functions $f_{1}$ to $f_{7}$ in Eq. (38) can be defined through knowledge elicitation. While these functions may interact in a synergistic manner, these interactions may be incorporated into the model if various rules can be formulated. For example, based on the analytical models and the knowledge gained from the experimental results it is possible to construct knowledge-based rules such as:

- stable particles decrease $R_{\mathrm{c}}$;

- homogeneous grain size distribution lowers $R_{\mathrm{c}}$ while heterogeneous grain size distribution increases $R_{\mathrm{c}}$;

- a heterogeneous particle distribution decreases $R_{\mathrm{c}}$;

- fine initial grain size may decrease $R_{c}$;

- high grain boundary energy and high g.b. mobility may decrease $R_{\mathrm{c}}$;

- non-spherical shaped particles lowers $R_{\mathrm{c}}$;

- an increase in boundary misorientation may increase $R_{\mathrm{c}}$, and

- an increase in temperature may have a mixed effect on $R_{\mathrm{e}}$.

The proposed global model would have applicability in many areas where grain growth is important. A typical example may include steel processing to predict the limiting grain size during slab reheating. The model may also be used with existing recrystallization models to calculate the limiting grain size in multi-pass hot rolling, or be used to assess grain size control during sintering of ceramic and metallic powders and during annealing of particle-containing alloys and ceramics. In general, the global model may be used in any application where a knowledge of the limiting grain size in particlecontaining materials is needed.

\section{Summary}

The Zener equation and its derivatives have been incorporated in theories dealing with recovery, recrystallization and grain growth in particle-containing materials. It has been used to describe annealing phenomena in a wide range of particle-containing materials including plain carbon steels, $\mathrm{Al} / \mathrm{Nb} / \mathrm{V} / \mathrm{Ti}$ treated microalloyed steels, Al-treated $\mathrm{C}-\mathrm{Mn}$ steels, maraging steels, sintered tool steels, Ni-based superalloys, Albase alloys, $\mathrm{Cu}$-base alloys, $\mathrm{Al}-\mathrm{Al}_{2} \mathrm{O}_{3}$ alloys, $\mathrm{Al}-\mathrm{Si}$ alloys, copper-based shape memory alloys, Ti-base alloys, PMMCs and in a number of ceramic materials.

Modifications of Eq. (1) have shown that the value of $K($ for $m=1$ ) is lower than that given by Zener and the value of $m$ lies in the range $0.3<m<1.0$. In comparison with the original equation it has been found that $F_{\mathrm{z}}$ is either lower or higher, $n_{\mathrm{s}}$ higher, $P_{z}$ much higher and $P_{\mathrm{g}}$ lower than the original estimate. For the range of volume fractions of particles present in most engineering materials $(f<0.1)$ the consequence of these modifications is a predicted limiting grain radius smaller than that given by the original equation. Although most of the modifications exhibit similar functional dependence of $R_{\mathrm{c}}$ to $r / f$, with typical values of $K$ and $m$ (for $f<0.05$ ) being 0.17 and 1.0 respectively, it is likely that the future form of the Zener equation may be based on the artificial intelligence techniques.

\section{Acknowledgements}

The authors would like to thank Professor $M$. Hatherly, University of New South Wales, Australia for critically reviewing the manuscript and Professor F. J. Humphreys, Manchester Materials Science Centre, UK for many valuable comments.

\section{Nomenclature}

$\alpha$ : geometric constant

$D$ : grain diameter

$D_{\mathrm{R}}$ : recrystallized grain diameter

$e:$ base of natural logarithm

$\varepsilon:$ particle eccentricity, strain

$\dot{8}:$ strain rate

$f:$ volume fraction of particles

$\phi$ : fraction of particles on a grain boundary

$F_{\mathrm{z}}$ : Zener pinning force due to a single particle on the grain boundary

$F_{\mathrm{z}}^{\mathrm{s}}$ : maximum pinning force due to a spherical particle with same volume as an ellipsoid

g.b.: grain boundary

$\gamma$ : energy per unit area of a grain boundary (surface tension of a grain boundary, $\mathrm{J} / \mathrm{m}^{2}$ )

$I$ : dirt factor in Fullman's theory

$K$ : dimensionless constant in the Zener equation

$\lambda$ : mean linear intercept

$m$ : exponent for $f$ in the general form of the Zener equation

$M$ : boundary mobility

$n_{\mathrm{s}}$ : number of particles per unit area of a grain boundary (surface density of particles)

$n_{\mathrm{v}}$ : number of particles per unit volume

$\eta_{\mathrm{c}}$ : critical particle size for particle stimulated nucleation (PSN)

$P$ : net pressure on a boundary

$P_{\mathrm{C}}$ : retarding pressure due to boundary curvature

$P_{\mathrm{D}}$ : driving pressure for recrystallization

$P_{\mathrm{g}}:$ driving pressure for grain growth

$P_{\mathrm{z}}$ : Zener pinning pressure due to all particles on a grain boundary

$R$ : grain radius

$r$ : particle radius

$r_{\text {crit }}$ : critical particle radius at unpinning

$R_{\text {cr }}$ : critical minimum grain radius for grain growth to occur according to Hillert's theory

$R_{\mathrm{c}}$ : limiting grain radius at the inhibition of grain growth (Zener limit)

$T$ : absolute temperature

$\rho$ : radius of curvature of a grain boundary

$\rho_{\text {net }}$ : net radius of curvature of a grain boundary

$v$ : velocity of grain boundary migration 
$z:$ Zener factor $(3 f / 4 r)$

$Z$ : Gladman's heterogeneity factor $\left(R_{\text {max }} / R_{\text {mean }}\right)$

\section{REFERENCES}

1) C. S. Smith: Trans. AIME, 175 (1948), 15.

2) R. E. Reed-Hill and R. Abbaschian: Physical Metallurgy Principles, 3rd Ed., PWS-Kent Publishing, USA, (1992), 262.

3) T. Gladman: Proc. R. Soc. London, A294 (1966), 298.

4) E. Nes, N. Ryum and O. Hunderi: Acta Metall., 33 (1985), 11.

5) R. L. Fullman: Metal Interfaces, ASM, (1952), 179.

6) M. Hillert: Acta Metall., 13 (1965), 227.

7) T. Gladman and F. B. Pickering: J. Iron Steel Inst., 205 (1967), 653.

8) N. A. Haroun and D. W. Budworth: J. Mater. Sci., 3 (1968), 326.

9) K. G. Wold and F. M. Chambers: J. Aust. Inst. Met., 13 (1968), 79.

10) M. F. Ashby, J. Harper and J. Lewis: Trans. Metall. Soc. AIME, 245 (1969), 413.

11) P. Hellman and M. Hillert: Scand. J. Metall., 4 (1975), 211.

12) L. Anand and J. Gurland: Metall. Trans. ASM, 6A (1975), 928.

13) P. M. Hazzledine, P. B. Hirsch and N. Louat: Proc. Ist Int. Symp. on Metallurgy and Materials Science, ed. by N. Hansen et al., Risø National Laboratory, Roskilde, Denmark, (1980), 159.

14) O. Hunderi and N. Ryum: Acta Metall., 30 (1982), 739.

15) N. Louat: Acta Metall., 30 (1982), 1291.

16) R. D. Doherty: Met. Sci. J., 16 (1982), 1.

17) N. Ryum, O. Hunderi and E. Nes: Scr. Metall., 17 (I983), 1281.

18) D. J. Srolovitz, M. P. Anderson, G. S. Grest and P. S. Sahni: Acta Metall., 32 (1984), 1429.

19) H. M. Chan and F. J. Humphreys: Acla Metall., 32 (1984), 235.

20) P. R. Rios: Acta Metall, 35 (1987), 2805.

21) R. D. Doherty, D. J. Sroloviz, A. D. Rollet and M. P. Anderson: Scr. Metall., 21 (1987), 675.

22) M. Hillert: Acta Metall., 36 (1988), 3177.

23) R. Elst, J. Van Humbeeck and L. Delaey: Acta Metall, 36 (1988), 1723.

24) M. P. Anderson, G. S. Grest, R. D. Doherty, K. Li and D. J. Srolovitz: Scr. Metall., 23 (1989), 753.

25) S. P. Ringer, W. B. Li and K. E. Easterling: Acta Metall., 37 (1989), 831

26) O. Hunderi, E. Nes and N. Ryum: Acta Metall., 37 (1989), 129.

27) M. P. Hazzledine and R. D. J. Oldershaw: Philos. Mag., A61 (1990), 579.

28) G. N. Gassold, E. A. Holm and D. J. Srolovitz: Scr. Metall., 24 (1990), 101

29) B. R. Patterson and Y. Liu: Metall. Trans. ASM, 23A (1992), 2481.

30) C. J. Tweed, N. Hansen and B. Ralph: Metall. Trans. ASM, 14A (1983), 2235.

31) Y. Liu and B. R. Patterson: Scr. Metall., 27 (1992), 539.

32) P. A. Manohar, D. P. Dunne and T. Chandra: ISIJ Int., 36 (1996), 194.

33) Y. Liu and B. R. Patterson: Acta Mater., 44 (1996), 4327.

34) Y. Liu and B. R. Patterson: Scr. Metall., 29 (1993), 1101.

35) P. R. Rios: Scr. Mater., 34 (1996), 1185.

36) J. Gao, R. G. Thompson and B. R. Patterson: Acta Mater., 45 (1997), 3653.

37) P. A. Manohar: Ph. D. Thesis, University of Wollongong, (1997), 156.

38) B. K. Kad and P. M. Hazzledine: Mater. Sci. Eng., A238 (1997), 70.

39) O. Hunderi and N. Ryum: Acta Metall. Mater., 40 (1992), 543.

40) L. C. Stearns and M. P. Harmer: J. Am. Ceram. Soc., 79 (1996), No. 12,3020 .

41) F. J. Humphreys and M. Hatherly: Recrystallization and Related Annealing Phenomena, Elsevier Science, Oxford, UK, (1995).

42) P. Feltham: Acta Metall., 5 (1957), 97.

43) J-H Han and D-Y Kim: Acta Metall., 43 (1995), 3185.

44) G. Gottstein and L. S. Shvindlerman: Acta Metall. Mater., 41 (1993), 3267.

45) A. R. Jones and N. Hansen: Acta Metall., 29 (1981), 589.
46) S. K. Chang: Mater. Sci. Technol., 8 (1992), 760

47) R. D. Doherty and J. W. Martin: J. Iron Steel Inst., 91 (1962), 332.

48) E. Nes: Acta Metall., 24 (1976), 391.

49) P. L. Morris and B. J. Duggan: Met. Sci., 10 (1978), 1.

50) D. J. Lloyd: Met. Sci., 16 (1982), 304.

51) F. J. Humphreys: Acta Metall., 25 (1977), 1323.

52) F. J. Humphreys: Met. Sci. J., 13 (1979), 136.

53) F. J. Humphreys: Proc. Ist Int. Symp. on Metallurgy and Materials Science, ed. by N. Hansen et al., Risø National Laboratory, Roskilde, Denmark, (1980), 35.

54) F. G. Arieta and C. M. Sellars: Proc. of Int. Symp. on Low Carbon Steels for the 90's, ed. by R. Asfahani and G. Tither, TMS, Pittsburgh, (1993), 101.

55) E. J. Palmiere, C. I. Garcia and A. J. DeArdo: Metall. Trans. $A S M, 27$ A (1996), 951.

56) R. H. Palma, V. Martinez and J. J. Urcola: Powder Metall., 32 (1989), 291.

57) N. E. Hannerz and F. de Kazinczy: J. Iron Sleel Inst., 208 (1970), 475.

58) A. Yoshie, M. Fujioka, Y. Watanabe, K. Nishioka and H. Morikawa: ISIJ Int., 32 (1992), 395

59) W. J. Liu and J. J. Jonas: Proc. Int. Symp. on Physical Metallurgy and Thermomechanical Processing of Steels and Other Metals, "Thermec '88", ed. by I. Tamura, ISIJ, Tokyo, (1988), 90.

60) T. Gladman: Heat Treat. Met., 1994.1 (1994), 11.

61) G. Muralidharan and R. G. Thompson: Ser, Mater., 36 (1997), 755.

62) G. T. Grewal and J. Ankem: Acta Metall, 38 (1990), 1607.

63) C. H. Worner and P. M. Hazzledine: J. Met., 44 (1992), 16.

64) T. Gladman: J. Mater., 44 (1992), No. 2, 21.

65) T. George and J. J. Irani: J. Aust. Inst. Met., 13 (1968), 94.

66) E. J. Palmiere, C. I. Garcia and A. J. DeArdo: Metall. Trans. ASM, 25A (1994), 277.

67) B. Feng: Ph. D. Thesis, University of Wollongong, (1990).

68) T. Gladman: Ironmaking Steelmaking, 16 (1989), 241.

69) T. Gladman, I. D. Mclver and F. B. Pickering: J. Iron Steel Inst., 209 (197I), 380.

70) T. Siwecki, S. Zajac and G. Engberg: Proc. of 37th Mechanical Working and Steel Processing Conf., Vol. XXXIII, ISS, Hamilton, Canada, (1995), 635.

71) L. Erasmus: J. Iron Steel Inst, 202 (1964), 128.

72) D. Webster and G. B. Allen: J. Iron Steel Inst., 200 (1962), 520.

73) M. M. Ali Bepari: Metall. Trans. ASM, 20A (1989), 13.

74) J. M. Cabrera, A. Al Omar and J. M. Prado: J. Mater. Sci, 31 (1996), 1303

75) I. Anderson, O. Grong and N. Ryum: Acta Metall, 43 (1995), 2689.

76) P. R. Rios: Acta Metall., 40 (1992), 649.

77) P. R. Rios: Acta Metall., 42 (1994), 839.

78) P. R. Rios: Acta Mater., 45 (1997), 1785

79) P. A. Manohar and T. Chandra: Proc. of Australasia-Pacific Forum on Intelligent Processing and Manufacturing of Materials (IPMM '97), ed. by T. Chandra et al., Gold Coast, Australia, (1997), 1200

80) F. J. Humphreys: Acta Mater., 45 (1997), 4231.

$81)$ F. J. Humphreys: Acta Mater., 45 (1997), 5031.

82) S. Benum and E. Nes: Acta Mater., 45 (1997), 4593.

83) R. L. Higginson, M. Aindow and P. S. Bate: Mater. Sci. Eng., A225 (1997), 9.

84) T. Furu, K. Marthinsen and E. Nes: Mater. Sci. Forum, 113-115 (1993), 41.

85) J. A. Wert and L. K. Austin: Metall. Trans. ASM, 19A (1988), 617.

86) E. Nes and W. H. Hutchinson: Proc. $10^{\text {th }}$ Int. Symp. on Metallurgy and Materials Science, ed. by J. B. Bilde-Sorensen et al., Risø National Laboratory, Roskilde, Denmark, (1990), 233.

87) T. Gladman: Proc. 1st Int. Symp. on Metallurgy and Materials Science, ed. by N. Hansen et al., Risø National Laboratory, Roskilde, Denmark, (1980), 183.

88) A. K. Kaul and F. B. Pickering: Acta Metall, 30 (1982), 1303.

89) F. J. Humphreys and H. M. Chan: Mater. Sci. Technol., 12 (1996), 143. 